\title{
Does immunosuppressant medication lower blood pressure and arterial stiffness in patients with chronic kidney disease? An observational study
}

\author{
Charles J Ferro ${ }^{1}$, Nicola C Edwards ${ }^{2}$, Colin Hutchison ${ }^{1}$, Paul Cockwell ${ }^{1}$, Rick P Steeds ${ }^{2}$, Caroline O Savage ${ }^{1}$, \\ Jonathan N Townend ${ }^{2}$ and Lorraine Harper ${ }^{1}$
}

Chronic kidney disease is a proinflammatory state associated with increased arterial stiffness. We hypothesized that chronic kidney disease patients on long-term immunosuppression would have lower arterial stiffness and require treatment with less antihypertensive medication compared with non-immunosuppressed patients. A total of 254 patients (97 on immunosuppression) with chronic kidney disease were recruited from specialist renal clinics. Brachial blood pressure, central aortic pressure and waveform and pulse wave velocity were measured. Age, peripheral blood pressure and pulse wave velocity increased with worsening renal function but were not different between immunosuppressed and non-immunosuppressed patients. Central systolic $(P<0.001)$ and pulse pressure $(P=0.003)$ and the number of antihypertensive medications $(P<0.001)$ increased with worsening renal function and were higher in non-immunosuppressed patients $(P=0.02, P=0.004$ and $P<0.001$, respectively). Age, mean arterial pressure, number of antihypertensive medications and a diagnosis of diabetes were found to be independent predictors of pulse wave velocity $\left(R^{2}=0.375 ; P<0.001\right)$. In a subgroup of 30 patient pairs without diabetes mellitus and cardiovascular disease and with a proven renal diagnosis, carefully matched for age, gender, renal function and systolic pressure, the prescribed antihypertensive medication remained lower in the immunosuppressed patients compared with nonimmunosuppressed patients $(P=0.04)$. Pulse wave velocity was lower in the immunosuppressed group $(7.5 \pm 1.8$ vs. $8.8 \pm 1.9 \mathrm{~m} \mathrm{~s}^{-1} ; P=0.02$ ). This study suggests that immunosuppression might be a method of reducing blood pressure and arterial stiffness in patients with chronic kidney disease.

Hypertension Research (2011) 34, 113-119; doi:10.1038/hr.2010.193; published online 21 October 2010

Keywords: arterial stiffness; blood pressure; cardiovascular disease; chronic inflammation; chronic kidney disease; immunosuppression

\section{INTRODUCTION}

Cardiovascular disease is the leading cause of morbidity and mortality in patients with chronic kidney disease (CKD). Indeed, the risk of death from a cardiovascular event is far greater than the risk of progression to end-stage renal failure. ${ }^{1}$ Even after adjusting for traditional cardiovascular risk factors, there is a higher rate of cardiovascular events in patients with CKD than in healthy subjects, which suggests that additional mechanisms are responsible for this excess risk. ${ }^{1}$ The relationship between inflammation and cardiovascular disease in the general population is well established. ${ }^{1,2} \mathrm{CKD}$ is a proinflammatory state and evidence is accumulating to support a pathogenic role for inflammation in the increased risk of cardiovascular disease associated with this condition. ${ }^{1,2}$ Interestingly, in patients with other inflammatory diseases, such as rheumatoid arthritis ${ }^{3}$ or systemic lupus erythematosus, ${ }^{4}$ the increased use of immunosuppression is associated with a reduction in surrogate markers of cardiovascular risk.
Increased arterial stiffness is a powerful, independent predictor of cardiovascular morbidity and mortality, ${ }^{5}$ and may be important in driving the increased cardiovascular risk associated with CKD. ${ }^{6}$ It is raised in various clinical conditions such as rheumatoid arthritis ${ }^{7}$ and active systemic vasculitis ${ }^{8}$ and in patients with renal disease. ${ }^{9-13}$ Arterial stiffness may be reversible, at least to a degree, and a reduction in stiffness is associated with improved survival. ${ }^{14,15}$ Patients with rheumatoid arthritis treated with immunosuppressant anti-tumor necrosis factor therapy showed a reduction in large artery stiffness to levels similar to that found in healthy controls. ${ }^{3}$

Carotid-femoral pulse wave velocity (PWV) has been identified by expert consensus as the gold standard for measuring arterial stiffness. ${ }^{5}$ Measures derived from pulse wave analysis (central systolic and pulse pressure, systolic augmentation pressure and the augmentation index (AIx)) are also considered indirect, surrogate markers of arterial stiffness and provide additional information on arterial wave reflections. ${ }^{5}$ These

${ }^{1}$ Department of Nephrology, University of Birmingham and University Hospital Birmingham, Birmingham, UK and ${ }^{2}$ Department of Cardiology, University of Birmingham and University Hospital Birmingham, Birmingham, UK

Correspondence: Dr CJ Ferro, Department of Nephrology, University Hospital Birmingham, Vincent Drive, Birmingham B15 2TH, UK.

E-mail: Charles.Ferro@uhb.nhs.uk

Received 16 March 2010; revised 26 June 2010; accepted 24 July 2010; published online 21 October 2010 
surrogate markers are emerging as powerful predictors of cardiovascular mortality and events in dialysis and hypertensive patients as well as in patients with established coronary artery disease. ${ }^{5}$

CKD patients are known to have increased arterial stiffness that may be mediated by the uremic inflammatory environment. We hypothesized that CKD patients on long-term immunosuppressive treatment would have reduced arterial stiffness compared with non-immunosuppressed CKD patients and that this is mediated by a reduction of inflammation. Given that arterial stiffness and blood pressure are strongly interlinked and that CKD patients are treated to nationally set blood pressure targets, ${ }^{16}$ we also hypothesized that patients on long-term immunosuppression would require treatment with less antihypertensive medication.

\section{METHODS}

\section{Patients}

A total of 254 patients were recruited from specialist renal clinics at the University Hospital Birmingham from May 2004 to October 2007. All patients with CKD as defined by the Kidney Dialysis Quality Outcomes Initiative, ${ }^{17}$ and stable renal function (defined as a change in glomerular filtration rate (GFR) of $<5 \mathrm{ml} \mathrm{min}^{-1}$ per $1.73 \mathrm{~m}^{2}$ in the preceding 3 months) with no change in medication in the preceding 3 months were eligible for inclusion. Patients with atrial fibrillation, known left ventricular dysfunction or with signs and symptoms of congestive heart failure were excluded. Patients were classified as being on chronic immunosuppression if they had been on an immunosuppressant agent (prednisolone, azathioprine, mycophenolic acid) for $>6$ months prior to enrolment. A 6-month minimal treatment period was selected to exclude patients on short courses for renal or non-renal indications. A minimum of 6 months was also considered a reasonable period for chronic oral immunosuppression to have any significant effect on blood pressure or arterial stiffness. Patients on calcinuerin inhibitors were excluded because of the known direct hemodynamic effects of these agents. GFR was estimated by the four-variable Modification of Diet in Renal Disease formula with serum creatinine recalibrated to be traceable to an isotope-derived mass spectroscopy method. ${ }^{18}$ All patients were treated to a target blood pressure of $140 / 90 \mathrm{~mm} \mathrm{Hg}$, or $130 / 80 \mathrm{~mm} \mathrm{Hg}$ if significant proteinuria (urinary albumin/creatinine ratio $>70 \mathrm{mg} \mathrm{mmol}^{-1}$ ), as per national guidelines. ${ }^{16}$ Approval for the study was obtained from the South Birmingham Research Ethics Committee and written informed consent obtained from each participant.

The presence of cardiovascular disease was defined as a history of myocardial infarction, treatment for angina, angiographically proven coronary artery disease, coronary artery bypass graft, percutaneous coronary angioplasty, hemorrhagic stroke, ischemic stroke, transient ischemic attack, carotid artery revascularization, intermittent claudication, angiographically proven peripheral artery surgery, aortic aneurysm, angiographically proven renal artery stenosis or renal artery revascularization.

\section{Peripheral blood pressure measurement}

Brachial artery pressure was measured in duplicate using validated oscillometric techniques (HEM-705CP; Omron Corp., Tokyo, Japan ${ }^{19}$ or Dinamap Procare 200, GE Healthcare, Milwaukee, WI, USA) ${ }^{20}$ according to the British Hypertension Society Guidelines. ${ }^{21}$

\section{Pulse wave analysis}

Central pressure waveforms were derived and analyzed using the technique of pulse wave analysis (SphygmoCor; Atcor Medical, Sydney, Australia) as previously described.22-24 In brief, a high-fidelity micromanometer (SPC-301; Millar Instruments, Houston, TX, USA) was used to flatten, but not occlude the radial artery using gentle pressure. Data were collected directly into a portable computer and, after $11 \mathrm{~s}$ of data capture, an averaged peripheral waveform, and a corresponding central waveform, was generated. The central waveform was then analyzed using the system software to determine the AIx and central aortic pulse pressure and systolic pressure. AIx represents the difference between the second and first peaks of the central pressure waveform in systole, expressed as a percentage of the pulse pressure. Values are reported as the mean of two stable readings. The method has been shown to be reproducible in both healthy subjects and in patients with renal impairment. ${ }^{22-24}$ Given the known effects of heart rate, the results for AIx were corrected to a heart rate of 75 beats per $\min \left(\mathrm{AIx}_{75}\right){ }^{25}$

\section{Pulse wave velocity}

Carotid-femoral PWV was measured using the SphygmoCor by sequentially recording electrocardiogram -gated carotid and femoral artery waveforms. The path length was calculated by subtracting the distance between the sternal notch and carotid recording site from the distance between sternal notch and femoral site. The method has been shown to be reproducible in both healthy subjects and in patients with renal impairment. ${ }^{22,26}$

\section{Laboratory parameters}

Highly sensitive C-reactive protein (hsCRP), cholesterol, glucose and albumin were measured using standard methodology.

\section{Statistical analysis}

Data were analyzed with SPSS software (version 16; SPSS, Chicago, IL, USA). Continuous variables were compared using either Student's $t$-test or one-way analysis of variance after $\log$ transformation for non-normally distributed variables. Categorical variables were compared using Pearson's $\chi^{2}$ test. Simple correlations were performed using Pearson's test. Because of the obligatory covariance between variables, multivariate analysis was performed using a stepwise method to determine the independent predictors of PWV and systolic blood pressure as in previous studies. ${ }^{27-29}$ Factors for the stepwise method were considered either because they were established or putative determinants of stiffness or were based on an initial regression analysis with an 'enter' model, whereby factors were included if they achieved a significance value of $<0.10$. Values are represented as means \pm s.d. or medians (interquartile range). A probability of $<0.05$ was considered significant.

PWV is in part blood pressure and heart rate dependent, and hence values were, adjusted for mean arterial pressure and heart rate at the time of measurement before further analysis. Adjustment was performed by a linear regression of the three variables. The residual values were then added to the mean PWV. ${ }^{27}$ Values presented were the adjusted measurements.

Studying 98 patients in each group would give us a $95 \%$ power to detect a difference of $0.4 \mathrm{~m} \mathrm{~s}^{-1}$ between groups based on our previously published work on arterial stiffness in CKD, ${ }^{30}$ where patients had a PWV of $8.3 \mathrm{~m} \mathrm{~s}^{-1}$ with the s.d. of 1.7 using a two-tailed test at the $5 \%$ significance level.

\section{RESULTS}

\section{Patient characteristics}

In all, 97 patients on immunosuppression (Wegener's granulomatosis 47 , microscopic polyangiitis 18 , systemic lupus erythematosus 10 and other 22) and 157 patients not on immunosuppression (IgA nephropathy 19, renovascular/hypertensive disease 19, reflux/obstructive nephropathy 18 , adult polycystic kidney disease 15 , focal segmental glomerulosclerosis 13, other glomerulonephritis 20, single kidney 10, diabetic nephropathy 7, interstitial nephritis 3 and small kidneys at presentation/unknown 33) were recruited. The clinical characteristics are summarized in Table 1. All except three patients on immunosuppression were receiving corticosteroids. Patients had been on continuous immunosuppressive treatment for a median of 45 months (range 6-162) months. No patients were taking non-steroidal anti-inflammatory drugs. There were no differences between the groups in sex, age, weight, height, prevalence of diabetes mellitus, history of cardiovascular disease and current or previous smoking history. Although mean arterial blood pressure was similar in both groups $(P=0.4)$, the average number of antihypertensive medications per patient was considerably less in the immunosuppressed group ( 2.3 vs. 1.4 agents; $P<0.001$; Table 1).

Biochemical variables are summarized in Table 1. Patients on immunosuppression had better kidney function than non-immunosuppressed patients with a GFR $\left(46 \pm 18\right.$ vs. $41 \pm 19 \mathrm{ml} \mathrm{min}^{-1}$ per 
Table 1 Patient demographics, cardiovascular history and risk factors and concurrent medication

\begin{tabular}{|c|c|c|c|}
\hline & $\begin{array}{l}\text { Immunosuppressed } \\
\qquad(\mathrm{n}=97)\end{array}$ & $\begin{array}{c}\text { Non-immuno } \\
\text { suppressed }(\mathrm{n}=157)\end{array}$ & P-value \\
\hline Male (\%) & $54(56)$ & $98(62)$ & 0.4 \\
\hline Age, years & $57 \pm 13$ & $59 \pm 12$ & 0.3 \\
\hline Weight, kg & $82 \pm 19$ & $81 \pm 15$ & 0.5 \\
\hline Height, m & $1.69 \pm 0.1$ & $1.70 \pm 0.1$ & 0.7 \\
\hline Diabetes mellitus (\%) & $12(13)$ & $18(11)$ & 0.4 \\
\hline Cardiovascular disease $(\%)^{a}$ & $18(19)$ & $25(16)$ & 0.6 \\
\hline Current smoker (\%) & $8(23)$ & $22(14)$ & 0.2 \\
\hline Previous smoker (\%) & $37(38)$ & $44(28)$ & 0.1 \\
\hline GFR, $\mathrm{ml} \mathrm{min}{ }^{-1}$ per $1.73 \mathrm{~m}^{2}$ & $46 \pm 18$ & $41 \pm 19$ & 0.02 \\
\hline Calcium $\left(\mathrm{mmol} \mathrm{I}^{-1}\right)$ & $2.35 \pm 0.15$ & $2.33 \pm 0.13$ & 0.3 \\
\hline Phosphate (mmol $\left.{ }^{-1}\right)$ & $1.16 \pm 0.28$ & $1.25 \pm 0.25$ & 0.01 \\
\hline CaxP product $\left(\mathrm{mmol}^{2}\right.$ per $\left.\mathrm{I}^{2}\right)$ & $2.72 \pm 0.60$ & $2.90 \pm 0.64$ & 0.03 \\
\hline $\operatorname{hsCRP}\left(m g I^{-1}\right)^{b}$ & $2.3(0.9-5.0)$ & $2.3(0.6-5.9)$ & 0.5 \\
\hline Total cholesterol, $\mathrm{mmol}^{-1}$ & $5.1 \pm 1.0$ & $4.6 \pm 1.2$ & $<0.001$ \\
\hline Glucose, $\mathrm{mmol}^{-1}$ & $6.0 \pm 2.0$ & $5.5 \pm 2.0$ & $<0.05$ \\
\hline ACR $\left(\mathrm{mg} \mathrm{mmol} \mathrm{m}^{-1}\right)^{\mathrm{b}}$ & $4.4(0.8-23.8)$ & $6.4(0.8-47.0)$ & 0.2 \\
\hline Statin (\%) & $43(45)$ & $75(48)$ & 1.0 \\
\hline Aspirin (\%) & $23(24)$ & $35(22)$ & 0.8 \\
\hline Warfarin (\%) & $9(9)$ & $4(3)$ & 0.04 \\
\hline Nitrate (\%) & $5(5)$ & $8(5)$ & 1.0 \\
\hline Oral corticosteroids (\%) & $93(97)$ & 0 & NA \\
\hline Azathioprine (\%) & $50(52)$ & 0 & NA \\
\hline Mycophenolic acid (\%) & $16(17)$ & 0 & NA \\
\hline $\begin{array}{l}\text { Mean no. of antihypertensive } \\
\text { medications/patient }\end{array}$ & $1.4 \pm 1.0$ & $2.3 \pm 1.3$ & $<0.0001$ \\
\hline$\beta$-blocker (\%) & $14(15)$ & $51(32)$ & 0.002 \\
\hline Diuretic (\%) & $33(34)$ & $71(45)$ & 0.2 \\
\hline$\alpha$-blocker (\%) & $7(7)$ & $32(20)$ & 0.007 \\
\hline Calcium channel blocker (\%) & $16(17)$ & $64(41)$ & $<0.001$ \\
\hline ARB (\%) & $10(10)$ & $48(31)$ & $<0.001$ \\
\hline ACEi (\%) & $53(55)$ & $86(55)$ & 0.9 \\
\hline Moxonidine (\%) & $1(1)$ & $7(4)$ & 0.3 \\
\hline Minoxidil (\%) & $0(0)$ & $1(1)$ & 1.0 \\
\hline Methyldopa (\%) & $0(0)$ & $1(1)$ & 1.0 \\
\hline
\end{tabular}

Abbreviations: $\mathrm{ACEi}$, angiotensin-converting enzyme inhibitor; ACR, albumin/creatinine ratio ARB, angiotensin receptor blocker; GFR, glomerular filtration rate; hsCRP, highly sensitive C-reactive protein.

Values are represented as mean \pm s.d. except for the values that were skewed. Significance was determined with unpaired two-tailed Student's $t$-test after log transformation for skewed variables and by Pearson's $\chi^{2}$ test for categorical variables.

aThe presence of cardiovascular disease is defined as a history of myocardial infarction, treatment for angina, angiographically proven coronary artery disease, coronary artery bypass graft, PTCA, hemorrhagic stroke, ischemic stroke, transient ischemic attack, carotid artery revascularization, intermittent claudication, angiographically proven peripheral artery surgery, aortic aneurysm, angiographically proven renal artery stenosis and renal artery revascularization.

aortic aneurysm, angiographically proven renal artery stenosis and renal artery revascularization.

$\left.1.73 \mathrm{~m}^{2} ; P=0.02\right)$. They also had higher serum glucose, total cholesterol and albumin and lower serum phosphate concentrations than the non-immunosuppressed CKD group. There were no differences between the groups with respect to hsCRP.

\section{Hemodynamics}

The hemodynamic parameters for both groups are summarized in Table 2. There were no significant differences in PWV or timing of the reflected wave between the two groups as a whole. Patients on immunosuppression had lower central augmentation pressure $(11 \pm 8$ vs. $15 \pm 8 \mathrm{~mm} \mathrm{Hg} ; P<0.001)$ and $\mathrm{AIx}(25 \pm 13$ vs. $30 \pm 10$; $P=0.002)$ than non-immunosuppressed CKD patients, although the difference in AIx was not significant when corrected for a heart rate of
Table 2 Hemodynamic parameters

\begin{tabular}{lccc}
\hline & $\begin{array}{c}\text { Imminosuppressed } \\
(\mathrm{n}=97)\end{array}$ & $\begin{array}{c}\text { Non-immunosuppressed } \\
(\mathrm{n}=157)\end{array}$ & P-value \\
\hline AP, mm Hg & $11 \pm 8$ & $15 \pm 8$ & $<0.001$ \\
Alx, \% & $25 \pm 13$ & $30 \pm 10$ & 0.002 \\
Alx $75, \%$ & $24 \pm 10$ & $26 \pm 10$ & 0.2 \\
Tr, s & $139 \pm 24$ & $140 \pm 13$ & 0.8 \\
PWV, m s & $8.7 \pm 2.7$ & $9.1 \pm 2.4$ & 0.2 \\
Peripheral SBP, mm Hg & $134 \pm 16$ & $140 \pm 21$ & 0.02 \\
Peripheral DBP, mm Hg & $80 \pm 11$ & $80 \pm 12$ & 0.9 \\
Peripheral PP, mm Hg & $54 \pm 13$ & $60 \pm 16$ & 0.002 \\
Peripheral MAP, mm Hg & $98 \pm 12$ & $100 \pm 14$ & 0.4 \\
Central SBP, mm Hg & $122 \pm 15$ & $129 \pm 20$ & 0.002 \\
Central DBP, mm Hg & $81 \pm 11$ & $81 \pm 12$ & 0.7 \\
Central PP, mm Hg & $42 \pm 15$ & $49 \pm 14$ & 0.001 \\
Central MAP, mm Hg & $97 \pm 13$ & $98 \pm 17$ & 0.6 \\
Peripheral PP/central & $1.34 \pm 0.13$ & $1.25 \pm 0.21$ & $<0.001$ \\
PP ratio & & & \\
Heart rate, b.p.m. & $73 \pm 14$ & $66 \pm 12$ & $<0.001$ \\
\hline
\end{tabular}

Abbreviations: Aix, augmentation index; Alx 75 , augmentation index adjusted for a heart rate of 75 beats per min; AP, augmentation pressure; b.p.m., beats per min; DBP, diastolic blood pressure; MAP, mean arterial pressure; $\mathrm{PP}$, pulse pressure; $\mathrm{PWV}$, pulse wave velocity; $\mathrm{SBP}$ systolic blood pressure; Tr, timing of reflected wave.

Values are represented as mean \pm s.d. Significance was determined with unpaired two-tailed Student's $t$-test.

75 b.p.m. ( $\operatorname{AIx}_{75}: 24 \pm 10$ vs. $\left.26 \pm 10 \% ; P=0.8\right)$. Peripheral pulse pressure was significantly lower in the patients on immunosuppressant medication than the non-immunosuppressed CKD patients. They also had lower central systolic $(122 \pm 15$ vs. $129 \pm 20 \mathrm{~mm} \mathrm{Hg} ; P=0.04)$ and pulse ( $42 \pm 15$ vs. $49 \pm 14 \mathrm{~mm} \mathrm{Hg} ; P=0.005)$ pressures than the nonimmunosuppressed patients. The pulse pressure amplification ratio (central pulse pressure/peripheral blood pressure) was lower in the immunosuppressed group $(P<0.001)$.

There were no significant differences in PWV between patients treated with steroids only $(n=31)$ or those taking steroids with azathioprine or mycophenolic acid $(n=63)$ (8.4 \pm 2.6 vs. $8.8 \pm$ $\left.2.9 \mathrm{~m} \mathrm{~s}^{-1} ; P=0.6\right)$. The number of antihypertensive medication was the same in both groups $(1.4 \pm 1.2$ vs. $1.4 \pm 1.0 ; P=1.0)$.

\section{Hemodynamics and GFR quintiles}

Because of the difference in renal function between the two groups, the whole cohort was divided into quintiles according to GFR (Table 3) and analyzed by two-way analysis of variance. Age, peripheral and central blood pressure, PWV and hsCRP all increased with worsening GFR. Neither augmentation pressure nor $\mathrm{AIx}_{75}$ increased with worsening GFR. The number of antihypertensives per patient increased with worsening renal function $(P<0.001)$.

\section{Impact of immunosuppression on hemodynamics within GFR quintiles}

Age and peripheral blood pressure were not different between immunosuppressed and non-immunosuppressed patients within each quintile (Table 3). PWV was not significantly higher in the nonimmunosuppressed patients compared with immunosuppressed patients within quintiles $(P=0.3)$. Other measures of arterial stiffness such as central systolic and pulse pressure were lower in the immunosuppressed group than in the non-immunosuppressed group ( $P=0.02$ and $P=0.004$, respectively). The pulse pressure amplification ratio was consistently lower in the immunosuppressed patients 
Table 3 Subject characteristics according to estimated GFR quintile for immunosuppressed (I) and non-immunosuppressed (C) patients

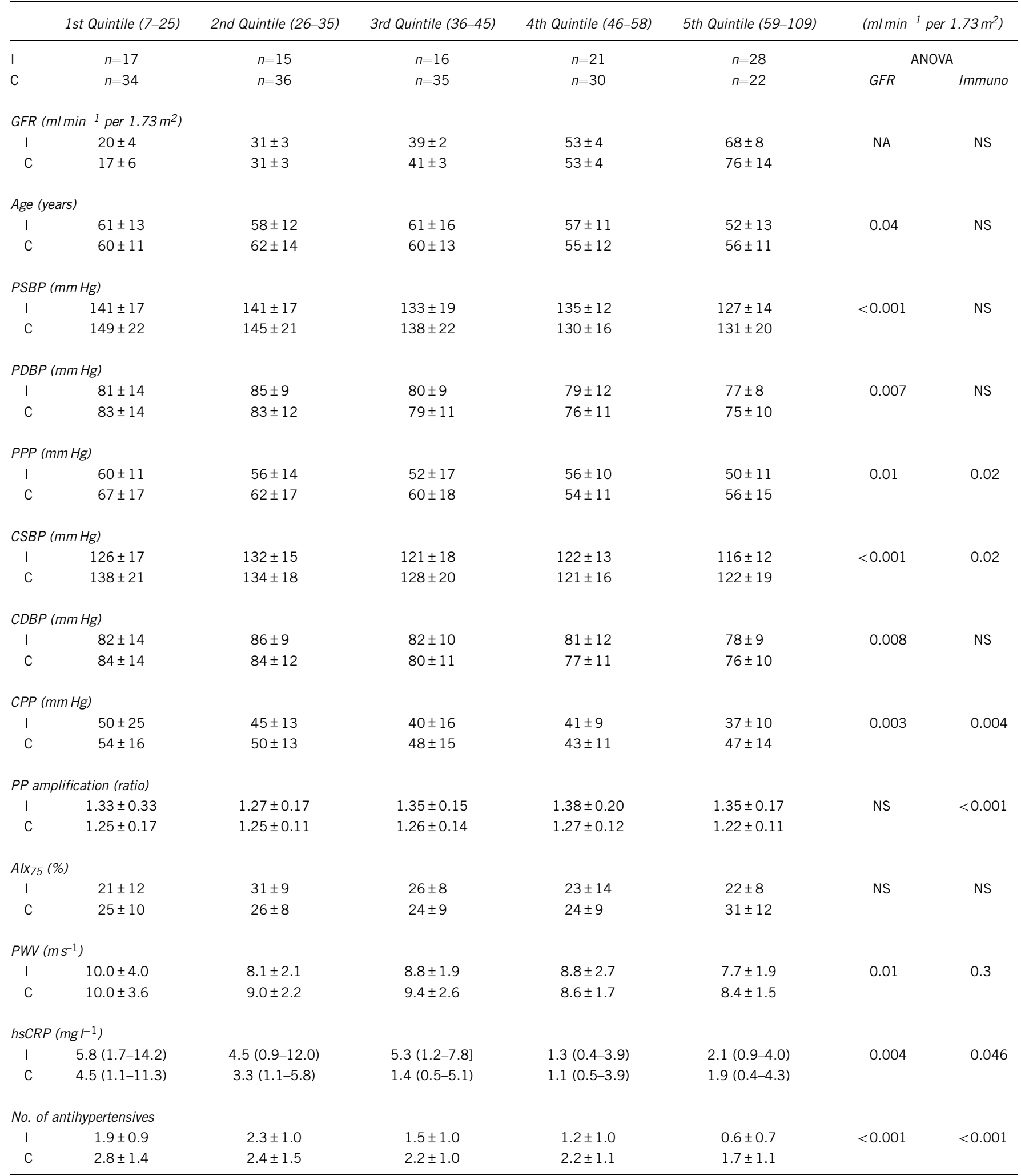

Abbreviations: Alx 75 , augmentation index adjusted for a heart rate of 75 beats per min; ANOVA, analysis of variance; CDBP, central diastolic blood pressure; CPP, central pulse pressure; CSBP, central systolic blood pressure; GFR, estimated glomerular filtration rate; hsCRP, highly sensitive C-reactive protein; NS, not significant; PDBP, diastolic blood pressure; PPP, peripheral pulse pressure; PSBP, peripheral systolic blood pressure; PWV, pulse wave velocity.

Data are mean \pm s.d. or median (interquartile range). hsCRP was log-transformed for analysis. Values in final column represent results of two-way ANOVA for estimated GFR and immunosuppression (immuno). 
Table 4 Patient demographics and hemodynamic data in $\mathbf{3 0}$ pairs of patients matched for sex, age, GFR and brachial systolic blood pressure after patients with a history of cardiovascular disease, diabetes mellitus or an unknown renal diagnosis have been excluded

\begin{tabular}{|c|c|c|c|}
\hline & $\begin{array}{l}\text { Immunosuppressed } \\
\quad(\mathrm{n}=30)\end{array}$ & $\begin{array}{c}\text { Non-immuno- } \\
\text { suppressed }(\mathrm{n}=30)\end{array}$ & P-value \\
\hline Male (\%) & $18(60)$ & $18(60)$ & 1.0 \\
\hline Age, years & $56 \pm 13$ & $56 \pm 13$ & 0.7 \\
\hline GFR, ml min-1 per $1.73 \mathrm{~m}^{2}$ & $46 \pm 14$ & $47 \pm 16$ & 0.4 \\
\hline Calcium (mmol $\left.{ }^{-1}\right)$ & $2.34 \pm 0.10$ & $2.34 \pm 0.13$ & 0.9 \\
\hline Phosphate $\left(\mathrm{mmol} \mathrm{l}^{-1}\right)$ & $1.12 \pm 0.26$ & $1.20 \pm 0.22$ & 0.3 \\
\hline CaxP product $\left(\mathrm{mmol}^{2}\right.$ per $\left.\mathrm{I}^{2}\right)$ & $2.60 \pm 0.61$ & $2.83 \pm 0.55$ & 0.3 \\
\hline $\operatorname{hsCRP}\left(\mathrm{mgl}^{-1}\right)^{\mathrm{a}}$ & $2.1(0.7-4.7)$ & $2.6(1.5-6.0)$ & 0.9 \\
\hline Total cholesterol, mmol I-1 & $5.2 \pm 0.9$ & $5.0 \pm 1.0$ & 0.1 \\
\hline Glucose, $\mathrm{mmol}^{-1}$ & $5.4 \pm 1.1$ & $5.0 \pm 0.8$ & 0.001 \\
\hline $\operatorname{ACR}\left(\mathrm{mg} \mathrm{mmol}^{-1}\right)^{\mathrm{a}}$ & $7.1(1.6-27.9)$ & $18.3(1.3-73.5)$ & 0.3 \\
\hline $\mathrm{Alx}_{75}, \%$ & $24 \pm 10$ & $24 \pm 11$ & 0.7 \\
\hline PWV, $\mathrm{ms}^{-1}$ & $7.5 \pm 1.8$ & $8.8 \pm 1.9$ & 0.02 \\
\hline Peripheral SBP, mm Hg & $134 \pm 15$ & $132 \pm 12$ & 0.7 \\
\hline Peripheral PP, mm Hg & $53 \pm 11$ & $55 \pm 10$ & 0.1 \\
\hline Central SBP, mm Hg & $122 \pm 13$ & $123 \pm 13$ & 0.7 \\
\hline Central PP, mm Hg & $39 \pm 10$ & $45 \pm 11$ & 0.04 \\
\hline Peripheral PP/central PP ratio & $1.36 \pm 0.19$ & $1.25 \pm 0.13$ & 0.01 \\
\hline $\begin{array}{l}\text { Mean no. of antihypertensive } \\
\text { medications/patient }\end{array}$ & $1.4 \pm 1.0$ & $2.1 \pm 1.5$ & 0.04 \\
\hline
\end{tabular}

Abbreviations: ACR, albumin/creatinine ratio; Alx 75 , augmentation index adjusted for a heart rate of 75 beats per min; GFR, estimated glomerular filtration rate; PP, pulse pressure; PWV, pulse wave velocity; SBP, systolic blood pressure.

Values are represented as mean \pm s.d. except for the values that were skewed. Significance was determined with paired two-tailed Student's $t$-test after log transformation for skewed variables and by Pearson's $\chi^{2}$ test for categorical variables.

avalues that are skewed are represented as median (interquartile range).

compared with the non-immunosuppressed patients $(P<0.001)$. Highly sensitive CRP was consistently higher in the immunosuppressed patients within quintiles, although this only just reached statistical significance $(P=0.046)$. The number of antihypertensives per patient was higher in the non-immunosuppressed patients in all quintiles $(P<0.001)$.

Impact of immunosuppression on hemodynamics in a matched cohort of CKD patients with a confirmed renal diagnosis but without diabetes mellitus or any evidence of cardiovascular disease Because the inclusion of patients with diabetes mellitus and cardiovascular disease may have confounded our results, we excluded all patients with these conditions. Moreover, we also excluded patients in whom the renal diagnosis was uncertain. From these patients, we carefully matched ${ }^{31}$ as many pairs from this group for gender, age (within 5 years), GFR (within $5 \mathrm{ml} \mathrm{min}^{-1}$ per $1.73 \mathrm{~m}^{2}$ ) and brachial systolic blood pressure (within $10 \mathrm{~mm} \mathrm{Hg}$ ). Thirty pairs were identified that fulfilled these criteria and their characteristics and hemodynamic data are presented in Table 4. As would be expected, both groups were well matched in age, GFR, gender and peripheral blood pressure. There were no differences in serum calcium or phosphate concentrations. The immunosuppressed group had lower central pulse pressure $(P=0.04)$ than the nonimmunosuppressed group, despite very similar peripheral pulse pressure. There were no differences in $\mathrm{AIx}_{75}$. PWV was higher in the non-immunosuppressed group than the immunosuppressed group $\left(8.8 \pm 1.9\right.$ vs. $\left.7.5 \pm 1.8 \mathrm{~m} \mathrm{~s}^{-1}: P=0.02\right)$. The mean number of antihypertensives was lower in the immunosuppressed group $(P=0.04)$.
Table 5 Multiple regression analysis for (a) PWV and (b) brachial systolic pressure

\begin{tabular}{|c|c|c|c|c|c|}
\hline & \multicolumn{2}{|c|}{$\begin{array}{c}\text { Unstandardized } \\
\text { coefficients }\end{array}$} & \multirow{2}{*}{$\begin{array}{c}\text { Standardized } \\
\text { coefficients } \\
\beta\end{array}$} & \multirow[b]{2}{*}{$T$} & \multirow[b]{2}{*}{ P-value } \\
\hline & $B$ & s.e. & & & \\
\hline \multicolumn{6}{|l|}{ (a) } \\
\hline Age (years) & 0.096 & 0.012 & 0.446 & 7.921 & $<0.001$ \\
\hline MAP (mm Hg) & 0.048 & 0.011 & 0.243 & 4.261 & $<0.001$ \\
\hline $\begin{array}{l}\text { Number of antihypertensive } \\
\text { medications }(n)\end{array}$ & 0.480 & 0.121 & 0.227 & 3.968 & $<0.001$ \\
\hline Diagnosis of diabetes & 1.203 & 0.481 & 0.142 & 2.503 & 0.013 \\
\hline \multicolumn{6}{|l|}{ (b) } \\
\hline $\mathrm{PWV}\left(\mathrm{ms}^{-1}\right)$ & 2.568 & 0.489 & 0.343 & 5.253 & $<0.001$ \\
\hline eGFR $\left(\mathrm{ml} \mathrm{min}-1\right.$ per $\left.1.73 \mathrm{~m}^{2}\right)$ & -0.23 & 0.068 & -0.224 & -3.44 & 0.001 \\
\hline
\end{tabular}

Abbreviations: MAP, mean arterial pressure; GFR, estimated glomerular filtration rate; PWV,

pulse wave velocity.

Adjusted $R^{2}=0.375, P<0001$ in (a). Adjusted $R^{2}=0.22, P<0001$ in (b).

Determinants of unadjusted pulse wave velocity and brachial systolic blood pressure

In univariate analysis, PWV was not associated with the use of immunosuppressant therapy but was positively correlated with age, history of cardiovascular disease, diagnosis of diabetes mellitus, number of antihypertensive drugs, mean arterial pressure, hsCRP, and negatively with GFR $(r=-0.25, P<0.001)$ at the $<5 \%$ level. In a stepwise regression model for PWV (Table 5a), age, mean arterial pressure, number of antihypertensive medications and a diagnosis of diabetes were found to be independent predictors $\left(R^{2}=0.375\right.$; $P<0.001$ ).

In univariate analysis, brachial systolic blood pressure was positively associated with age, history of cardiovascular disease, diagnosis of diabetes mellitus, number of antihypertensive drugs, hsCRP, PWV and negatively with GFR at the $<5 \%$ level. In a stepwise regression model for brachial systolic blood pressure (Table 5b), PWV and estimated GFR were found to be independent predictors $\left(R^{2}=0.22 ; P<0.001\right)$.

Serum calcium and phosphate concentrations and the calciumphosphate product were not associated with PWV or brachial systolic pressure in univariate analysis and were not independent predictors in either regression model.

\section{DISCUSSION}

This study found a significant difference in PWV, the generally accepted gold standard measure of arterial stiffness, between closely matched non-diabetic immunosuppressed and non-immunosuppessed CKD patients without cardiovascular disease. This study also supports our secondary hypothesis that immunosuppressed CKD patients require treatment with less antihypertensive agents than non-immunosuppressed patients. Patients with known CKD are treated to achieve nationally set blood pressure targets, and thus our study provides some indirect support to the theory that treatment with immunosuppressant medication lowers blood pressure in CKD patients. However, an interventional study would be required to prove this.

Our stepwise regression model for PWV has an $R^{2}$ value of 0.375 , which is comparable to other major studies in disease states. ${ }^{29}$ This does leave a significant amount of variability, and other factors, such as disorders of calcium-phosphate metabolism, require further 
investigation in future studies. ${ }^{32}$ In this study the main determinants of PWV in the general population, including diabetes, still hold true for our patients with CKD, with some notable exceptions. ${ }^{28}$ The influence of sex appears to have been lost and the number of antihypertensive medications taken is associated with higher PWV. However, there are several well-documented problems with the use of stepwise regression analysis and it is possible that several factors may have been excluded from the final model inappropriately. ${ }^{33-35}$ Most antihypertensives either improve or have a neutral effect on arterial stiffness. ${ }^{36}$ Interestingly, we have shown lower use of antihypertensive agents across most GFR quintiles in patients on immunosuppression treatment associated with lower PWV. There are now several reports that immunosuppression lowers blood pressure in non-immunological experimental models of hypertension and renal disease. ${ }^{37}$ There is also an intriguing preliminary report of mycophenolate mofetil lowering blood pressure in eight patients with rheumatoid arthritis or psoriasis. ${ }^{38}$ However, to the best of our knowledge, this is the first report in which long-term immunosuppression appears to be associated with reduced use of antihypertensive medication in a human population. Interestingly, a recent report showed that PWV is lowered by immunosuppression in patients with rheumatoid arthritis independently of blood pressure. ${ }^{3}$

Patients on immunosuppression had higher single measurement hsCRP than non-immunosuppressed patients across the quintiles of renal function as previously reported. ${ }^{39}$ Whether this finding reflects ongoing increased inflammation or reflects that hsCRP is a poor marker of inflammation in a number of conditions is unclear. Given that it just reached statistical significance with a $P$-value of only 0.046 suggests it requires confirmation in a larger study. An interventional study would hopefully elucidate any potential mechanisms for this. However, studies of arterial stiffness in rheumatoid suggest controversy in the relative importance of current ${ }^{3,7} v s$. historical inflammation. ${ }^{40,41}$

In this study GFR was associated with systolic blood pressure and PWV in univariate analysis. However, GFR was associated with systolic blood pressure in univariate and multivariate analyses. Pulse pressure is considered a surrogate marker of arterial stiffness. ${ }^{5}$ We have found that central and brachial pulse pressures were lower in the immunosuppressed group, resulting in higher pulse pressure amplification. This might have significant prognostic implications. ${ }^{5,42}$

The immunosuppressed group had higher cholesterol and glucose levels, with one possible explanation being the use of continuous corticosteroid treatment. Hypercholesterolemia and diabetes are both associated with increased arterial stiffness, ${ }^{43,44}$ and these associations may have also contributed to further clouding any potential association between lower arterial stiffness and immunosuppressant use, as indeed would have been the adverse vascular effects of corticosteroids. ${ }^{45}$ Several studies have reported an association between corticosteroid treatment and increased cardiovascular risk. ${ }^{45}$ However, use of methotrexate in patients with rheumatoid arthritis is associated with reduced intima-media thickness and reduced cardiovascular mortality. ${ }^{46,47}$ Similarly, use of cyclophosphamide is negatively associated with atheromatous plaque in patients with systemic lupus erythematosus. ${ }^{4}$ Thus, it is possible that different immunosuppressive agents may have different overall effects on cardiovascular risk, with any arterial stiffness lowering effects being counteracted by atheroma and increased arterial stiffness promoting actions of corticosteroids such as hyperglycemia and hypercholesterolemia. All but three of our immunosuppressed patients were taking steroids. Thus, it was not possible to examine the effects of steroid-free immunosuppression in our cohort.
There are limitations to our study. Its cross-sectional nature; the inclusion of patients with pre-existing cardiovascular disease; and the coexistence of treatment for inflammatory conditions, diabetes, hypertension and hypercholesterolemia may all have affected the results. However, this is the clinical reality of the patient who has CKD and is at high cardiovascular risk. We have done our best to minimize the impact of these potential confounders by repeating all the analyses excluding patients with any history of cardiovascular disease, diabetes mellitus, renovascular or hypertensive kidney disease and included only patients with a proven renal diagnosis. These analyses have confirmed our findings when all patients were studied and indeed appear to strengthen them. Despite our best efforts to correct for any factors that may have affected our results, we cannot be sure to have eliminated any residual confounding. GFR was not measured directly but calculated from serum creatinine and this may have affected the accuracy of the relationship described. Only use of antihypertensive drug category data were collected. Although it is possible that a systematic use of higher drug doses in one group may have affected the results, we believe this to be very unlikely given that all patients were being treated by the same group of physicians. Although PWV is the currently accepted gold standard measure for arterial stiffness, it is not without its limitations, especially in relation to patient factors such as obesity and peripheral artery disease. ${ }^{5}$ However, we have attempted to minimize any effect by very closely matching the groups. We emphasize that the observational nature of our study also only allows associations between parameters to be drawn, and causality cannot be implied.

Our data provide some support to the hypothesis that long-term use of immunosuppressive medication may reduce arterial stiffness and improve blood pressure control in patients with CKD. Our findings have implications for further research that could potentially markedly change the conventional management of these patients. The significantly increased cardiovascular risk associated with CKD is not totally accounted for by traditional risk factors. CKD is a proinflammatory state and chronic inflammation has long been associated with an increased cardiovascular risk in many different populations. The results of this study provide further support for an interventional study targeting inflammation in these patients.

\section{CONFLICT OF INTEREST}

The authors declare no conflict of interest.

\section{ACKNOWLEDGEMENTS}

This study was funded by grants from the British Heart Foundation and University Hospital Birmingham Charities Fund.

1 Schiffrin EL, Lipman ML, Mann JF. Chronic kidney disease: effects on the cardiovascular system. Circulation 2007; 116: 85-97.

2 Cachofeiro V, Goicochea M, de Vinuesa SG, Oubina P, Lahera V, Luno J. Oxidative stress and inflammation a link between chronic kidney disease and cardiovascular disease. Kidney Int 2008; 74(Suppl 111): S4-S9.

3 Maki-Petaja KM, Hall FC, Booth AD, Wallace SM, Yasmin, Bearcroft PW, Harish S, Furlong A, McEniery CM, Brown J, Wilkinson IB. Rheumatoid arthritis is associated with increased aortic pulse-wave velocity, which is reduced by anti-tumor necrosis factor-alpha therapy. Circulation 2006; 114: 1185-1192.

4 Roman MJ, Shanker BA, Davis A, Lockshin MD, Sammaritano L, Simantov R, Crow MK, Schwartz JE, Paget SA, Devereux RB, Salmon JE. Prevalence and correlates of accelerated atherosclerosis in systemic lupus erythematosus. N Engl J Med 2003; 349: 2399-2406.

5 Laurent S, Cockcroft J, Van Bortel L, Boutouyrie P, Giannattasio C, Hayoz D, Pannier B, Vlachopoulos C, Wilkinson I, Struijker-Boudier H. Expert consensus document on arterial stiffness: methodological issues and clinical applications. Eur Heart J 2006; 27: 2588-2605 
6 Covic A, Gusbeth-Tatomir P, Goldsmith DJ. Arterial stiffness in renal patients: an update. Am J Kidney Dis 2005; 45: 965-977.

7 Wong M, Toh L, Wilson A, Rowley K, Karschimkus C, Prior D, Romas E, Clemens L, Dragicevic G, Harianto H, Wicks I, McColl G, Best J, Jenkins A. Reduced arterial elasticity in rheumatoid arthritis and the relationship to vascular disease risk factors and inflammation. Arthritis Rheum 2003; 48: 81-89.

8 Booth A, Harper L, Hammad T, Bacon P, Griffith M, Levy J, Savage C, Pusey C, Jayne D. Prospective study of TNFalpha blockade with infliximab in anti-neutrophil cytoplasmic antibody-associated systemic vasculitis. J Am Soc Nephrol 2004; 15: 717-721.

9 Ohya Y, Iseki K, Iseki C, Miyagi T, Kinjo K, Takishita S. Increased pulse wave velocity is associated with low creatinine clearance and proteinuria in a screened cohort. Am J Kidney Dis 2006; 47: 790-797.

10 Mourad JJ, Pannier B, Blacher J, Rudnichi A, Benetos A, London GM, Safar ME. Creatinine clearance, pulse wave velocity, carotid compliance and essential hypertension. Kidney Int 2001; 59: 1834-1841.

11 Wang MC, Tsai WC, Chen JY, Huang JJ. Stepwise increase in arterial stiffness corresponding with the stages of chronic kidney disease. Am J Kidney Dis 2005; 45: 494-501.

12 Briet M, Bozec E, Laurent S, Fassot C, London GM, Jacquot C, Froissart M, Houillier P, Boutouyrie P. Arterial stiffness and enlargement in mild-to-moderate chronic kidney disease. Kidney Int 2006; 69: 350-357.

13 Edwards NC, Ferro CJ, Townend JN, Steeds RP. Aortic distensibility and arterialventricular coupling in early chronic kidney disease: a pattern resembling heart failure with preserved ejection fraction. Heart 2008; 94: 1038-1043.

14 Guerin AP, Blacher J, Pannier B, Marchais SJ, Safar ME, London GM. Impact of aortic stiffness attenuation on survival of patients in end-stage renal failure. Circulation 2001; 103: 987-992.

15 Williams B, Lacy PS, Thom SM, Cruickshank K, Stanton A, Collier D, Hughes AD, Thurston H, O'Rourke M. Differential impact of blood pressure-lowering drugs on central aortic pressure and clinical outcomes: principal results of the Conduit Artery Function Evaluation (CAFE) study. Circulation 2006; 113: 1213-1225.

16 Joint Specialty Committee on Renal Medicine of the Royal College of Physicians and the Renal Association and the Royal College of General Practitioners. Chronic Kidney Disease in Adults: UK Guidelines for Identification, Management and Referral. Royal College of Physicians: London, 2006.

17 National Kidney Foundation. K/DOQI clinical practice guidelines for chronic kidney disease: evaluation, classification and stratification. Am J Kid Dis 2002; 39(Suppl 2): S1-S246.

18 Levey AS, Bosch JP, Lewis JB, Greene T, Rogers N, Roth D. A more accurate method to estimate glomerular filtration rate from serum creatinine: a new prediction equation. Modification of Diet in Renal Disease Study Group. Ann Intern Med 1999; 130: 461-470.

19 O'Brien E, Mee F, Atkins N, Thomas M. Evaluation of three devices for self-measurement of blood pressure according to the revised British Hypertension Society Protocol: the Omron HEM-705CP, Philips HP5332, and Nissei DS-175. Blood Press Monit 1996; 1: 55-61.

20 Reinders A, Reggiori F, Shennan AH. Validation of the DINAMAP ProCare blood pressure device according to the international protocol in an adult population. Blood Press Monit 2006; 11: 293-296.

21 Williams B, Poulter NR, Brown MJ, Davis M, McInnes GT, Potter JF, Thom S. Guidelines for management of hypertension: report of the fourth working party of the British Hypertension Society 2004-BHS IV. J Hum Hypertens 2004; 18: 139-185.

22 Wilkinson IB, Fuchs SA, Jansen IM, Spratt JC, Murray GD, Cockcroft JR, Webb DJ. Reproducibility of pulse wave velocity and augmentation index measured by pulse wave analysis. J Hypertens 1998; 16: 2079-2084.

23 Ferro CJ, Savage T, Pinder SJ, Tomson CR. Central aortic pressure augmentation in stable renal transplant recipients. Kidney Int 2002; 62: 166-171.

24 Savage MT, Ferro CJ, Pinder SJ, Tomson CR. Reproducibility of derived central arterial waveforms in patients with chronic renal failure. Clin Sci (Lond) 2002; 103: 59-65.
25 Wilkinson IB, MacCallum H, Flint L, Cockcroft JR, Newby DE, Webb DJ. The influence of heart rate on augmentation index and central arterial pressure in humans. J Physiol 2000; 525(Pt 1): 263-270.

26 Wimmer NJ, Townsend RR, Joffe MM, Lash JP, Go AS. Correlation between pulse wave velocity and other measures of arterial stiffness in chronic kidney disease. Clin Nephrol 2007; 68: 133-143.

27 Ford ML, Tomlinson LA, Chapman TP, Rajkumar C, Holt SG. Aortic stiffness is independently associated with rate of renal function decline in chronic kidney disease stages 3 and 4. Hypertension 2010; 55: 1110-1115.

28 McEniery CM, Yasmin, Hall IR, Qasem A, Wilkinson IB, Cockcroft JR. Normal vascular aging: differential effects on wave reflection and aortic pulse wave velocity: the AngloCardiff Collaborative Trial (ACCT). J Am Coll Cardiol 2005; 46: 1753-1760.

29 McEniery CM, Yasmin, Wallace S, Maki-Petaja K, McDonnell B, Sharman JE, Retallick C, Franklin SS, Brown MJ, Lloyd RC, Cockcroft JR, Wilkinson IB. Increased stroke volume and aortic stiffness contribute to isolated systolic hypertension in young adults. Hypertension 2005; 46: 221-226.

30 Edwards NC, Steeds RP, Stewart PM, Ferro CJ, Townend JN. Effect of spironolactone on left ventricular mass and aortic stiffness in early-stage chronic kidney disease: a randomized controlled trial. J Am Coll Cardiol 2009; 54: 505-512.

31 Bland JM, Altman DG. Matching. Br Med J 1994; 309: 1128.

32 Ferro CJ, Chue CD, Steeds RP, Townend JN. Is lowering phosphate exposure the key to preventing arterial stiffening with age? Heart 2009; 95: 1770-1772.

33 Wang D, Zhang W, Bakhai A. Comparison of Bayesian model averaging and stepwise methods for model selection in logistic regression. Stat Med 2004; 23: 3451-3467.

34 Yang X, Belin TR, Boscardin WJ. Imputation and variable selection in linear regression models with missing covariates. Biometrics 2005; 61: 498-506.

35 Whittingham MJ, Stephens PA, Bradbury RB, Freckleton RP. Why do we still use stepwise modelling in ecology and behaviour? J Anim Ecol 2006; 75: 1182-1189.

36 Mahmud A, Feely J. Antihypertensive drugs and arterial stiffness. Expert Rev Cardiovasc Ther 2003; 1 : 65-78.

37 Johnson RJ, Feig DI, Nakagawa T, Sanchez-Lozada LG, Rodriguez-Iturbe B. Pathogenesis of essential hypertension: historical paradigms and modern insights. $J$ Hypertens 2008; 26: 381-391.

38 Herrera J, Ferrebuz A, MacGregor EG, Rodriguez-Iturbe B. Mycophenolate mofetil treatment improves hypertension in patients with psoriasis and rheumatoid arthritis. $J$ Am Soc Nephrol 2006; 17: S218-S225.

39 Don BR, Kaysen G. Serum albumin: relationship to inflammation and nutrition. Semin Dial 2004; 17: 432-437.

40 Van Doornum S, McColl G, Jenkins A, Green DJ, Wicks IP. Screening for atherosclerosis in patients with rheumatoid arthritis: comparison of two in vivo tests of vascular function. Arthritis Rheum 2003; 48: 72-80.

41 Klocke R, Cockcroft JR, Taylor GJ, Hall IR, Blake DR. Arterial stiffness and central blood pressure, as determined by pulse wave analysis, in rheumatoid arthritis. Ann Rheum Dis 2003; 62: 414-418.

42 Nijdam ME, Plantinga Y, Hulsen HT, Bos WJ, Grobbee DE, van der Schouw YT, Bots ML. Pulse pressure amplification and risk of cardiovascular disease. Am J Hypertens 2008; 21: 388-392.

43 Wilkinson IB, Prasad K, Hall IR, Thomas A, MacCallum H, Webb DJ, Cockcroft JR. Increased central pulse pressure and augmentation index in subjects with hypercholesterolemia. J Am Coll Cardiol 2002; 39: 1005-1011.

44 Wilkinson IB, MacCallum H, Rooijmans DF, Murray GD, Cockcroft JR, McKnight JA, Webb DJ. Increased augmentation index and systolic stress in type 1 diabetes mellitus. QJM 2000; 93: 441-448.

45 Walker BR. Glucocorticoids and cardiovascular disease. Eur J Endocrinol 2007; 157: 545-559.

46 Choi HK, Hernan MA, Seeger JD, Robins JM, Wolfe F. Methotrexate and mortality in patients with rheumatoid arthritis: a prospective study. Lancet 2002; 359: 1173-1177.

47 Wallberg-Jonsson S, Ohman M, Rantapaa-Dahlqvist S. Which factors are related to the presence of atherosclerosis in rheumatoid arthritis? Scand J Rheumatol 2004; 33: 373-379. 